Available online on 15.05.2020 at http://jddtonline.info
Open Access to Pharmaceutical and Medical Research
unrestricted non-commercial use, provided the original work is properly cited

Open@ Access

Research Article

\title{
Assessment of In Vitro Antidiabetic Potential of Purified Anthocyanin Extract from Floral Petals of Wild Balsam Species
}

\author{
R Arathy' ${ }^{1}$, Kurugan $^{2 *}, \mathrm{KV}$ Dinesh Babu ${ }^{3}$ and GS Manoj ${ }^{4}$ \\ $1 \& 4$ Department of Botany, Mahatma Gandhi College, Thiruvananthapuram, India \\ ${ }^{2 *}$ Center for Innovation in Science and Social Action, Thiruvananthapuram, India \\ ${ }^{3}$ Department of Chemistry, Govt. College for Women, Thiruvananthapuram, India
}

\begin{abstract}
Diabetes is a notorious and growing clinical and public health issue. The International Diabetes Federation assumes that 592 million had diabetes by 2035 and that by 2040 the number will increase to 642 million. Cardiovascular corollary accounts for four million deaths annually attributable to diabetes. Evidence reveals that certain glucose-lowering phytochemicals can improve vascular outcomes with type 2 diabetes, which, together with better understanding of using multiple therapies concurrently, offers opportunities for beneficial personalization of medication regimens. Anthocyanins are coloured pigments and are natural antioxidants. Keeping this in focus, this study was undertaken to evaluate the in vitro antidiabetic activity in the petals of wild Impatiens balsamina L. The anthocyanin was extracted from floral petals of wild balsam species and purified to homogeneity using chromatographic techniques. Evaluation of in vitro antidiabetic properties of anthocyanin extract revealed a dose-dependent increase in the inhibitory effect on the alpha-glucosidase $(200 \mu \mathrm{g} / \mathrm{ml})$ and alpha-amylase enzymes (500 $\mu \mathrm{g} / \mathrm{ml})$ and was comparable with the standard acarbose drug $(189 \mu \mathrm{g} / \mathrm{ml}$ and $50 \mu \mathrm{g} / \mathrm{ml})$. These results indicated that anthocyanin could be used as a source of functional food and nutraceuticals. This information from wild species will be useful in finding more potent antidiabetic principle from the natural resources for the clinical development of antidiabetic therapeutics. Future studies are planned to substantiate the antidiabetic power of anthocyanin using in vivo animal models.
\end{abstract}

Keywords: Alpha amylase, alpha glucosidase, diabetes, herbal remedies, Impatiens balsamina L.

Article Info: Received 03 March 2020; Review Completed 12 April 2020; $\quad$ Accepted 19 April 2020; $\quad$ Available online 15 May 2020

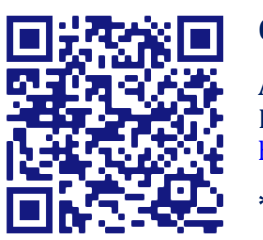

Cite this article as:

Arathy R, Murugan K, Dinesh Babu KV, Manoj GS, Assessment of In Vitro Antidiabetic Potential of Purified Anthocyanin Extract from Floral Petals of Wild Balsam Species, Journal of Drug Delivery and Therapeutics. 2020; 10(3):31-35 http://dx.doi.org/10.22270/jddt.v10i3.4050

*Address for Correspondence:

K Murugan, Director, Center for Innovation in Science and Social Action, Thiruvananthapuram.

\section{INTRODUCTION}

Currently, million in the earth suffered from diabetes as per the public health ${ }^{1}$. Further, the chance of diabetes is predicted to boom to 592 million by 2035 . It is one of the life style disorders that causes increasing mortality and is a global health issue of which type 2 diabetes (T2D) accounting $90 \%{ }^{2}$. It featured by hyperglycemia, will cause a severe metabolic disorder in glucose, lipid and protein levels. Furthermore, type 2 diabetes is also connected with many disorders such as nephropathy and cardiovascular and cerebro-vascular diseases ${ }^{3}$. Most of the diabetics possess hyperlipidemia i.e., blood has too many lipids (or fats), such as cholesterol and triglycerides. Moreover, many documented the induction of oxidative stress related to diabetes. Hyperglycemia induces reactive oxygen species (ROS) and reactive nitrogen species (RNS) will damage the pancreatic islet $\beta$-cell and their by insulin level. Insulin resistance and islet $\beta$-cell dysfunction are the critical reasons for diabetes, and therefore, mitigating oxidative stress to protection the cells may be an ideal way for T2D treatment. Nutraceutical along with drug therapy has been an effective strategy against diabetes.

Anthocyanins are flavonoid group of aqueous natural pigments exist in plants widely. They display antioxidant, anti-inflammatory, bactericidal, antiaging, antimetastatic, and protective effects on the liver, cardiovascular and cerebrovascular, and vision. Currently, synthetic drugs with antidiabetic effects like sulfonylureas, biguanides, and $\alpha$ glucosidase inhibitors groups are being used orally. The therapeutic support usage has multiple side effects like weight gain, hypoglycemia, gastrointestinal disturbances, liver and kidney damage, and hypersensitivity reactions 
which may have a negative impact on the response to treatment ${ }^{4}$. The high cost of antidiabetic therapies together with the myriad of adverse effects prompted the exploration of cheaper and more effective antidiabetic biomolecules from medicinal herbals. Some researchers suggested that the anthocyanins extract inhibits alpha amylase action, indicating that the molecules have unique function to suppress the increase in postprandial glucose content from $\operatorname{starch}^{5,6}$. The present study is aimed to investigate in vitro antidiabetic activities of the purified anthocyanin of wild Balsam species based on local claims regarding its use in the treatment of diabetes.

\section{MATERIALS AND METHODS}

\subsection{Plant materials}

For the whole study, the fresh healthy flowers of Impatiens balsamina L. (wild) collected from the natural habitats of hilly regions of Trivandrum, Kerala.

\subsection{Estimation of anthocyanin content}

$1 \mathrm{~g}$ flower was homogenized with acidified methanol (1\% $\mathrm{HCl})$ and the anthocyanin content was quantified by the standard protocol of Sutharut and Sudarat7. The absorbance of each dilution was read at 510 and $700 \mathrm{~nm}$ against distilled water as blank.

\subsection{Purification and characterization of anthocyanin from wild balsam}

Anthocyanin from fresh flowers of wild Balsam was extracted by acidified methanol (100\% Methanol: $1 \% \mathrm{HCl}$, 99:1, v/v) i.e., the petals were immersed in acidified methanol for overnight in dark at low temperature $\left(4^{\circ} \mathrm{C}\right)$. Subsequently, the crude solution obtained was filtered through cheese cloth and concentrated in rotary vacuum evaporator under vacuum at temperature not exceeding $40^{\circ} \mathrm{C}$. Then the aqueous extract was partitioned with ethyl acetate and the remaining water extract was concentrated in rotary vacuum evaporator, temperature not exceeding $40^{\circ} \mathrm{C}$. It was further fractionated by using Sephadex LH-20 followed by C18 as separation matrices. The aqueous extract was loaded on to a Sephadex LH-20 using 100\% methanol. Based on the TLC profile the fractions were subjected to purification by $\mathrm{C}-18$ open-column chromatography using acidified water $(1 \% \mathrm{HCl})$ and the column was eluted with a gradient of acidified methanol $(1 \% \mathrm{HCl})$ and water $[0: 100$ to 50:50]. From RP C-18 open-column chromatography, based on the TLC profile the pure fractions were concentrated and kept at low temperature $\left(-20^{\circ} \mathrm{C}\right)$. Purified anthocyanin from the wild Balsam was subjected to NMR analysis for their structural identification.

\subsection{In vitro antidiabetic activities}

\subsubsection{In vitro $\alpha$-glucosidase inhibition assay}

The $\alpha$-amylase and $\alpha$-glucosidase inhibitory effect of plant extracts was determined according to the protocol of Kim et $a l^{8}$. For alpha glucosidase inhibition, yeast $\alpha$-glucosidase was dissolved in $100 \mathrm{mM}$, pH 7.0 phosphate buffer, containing bovine serum albumin $2 \mathrm{~g} / \mathrm{l}$ and sodium azide $0.2 \mathrm{~g} / \mathrm{l}$ which was used as source of enzyme. Substrate used was paranitrophenyl- $\alpha$-d-glucopyranoside. Extract was weighed and serial dilutions of 50,100, 200, 400 and $500 \mu \mathrm{g} / \mathrm{mL}$ were made up with equal volumes of dimethylsulfoxide and distilled water. $10 \mu \mathrm{l}$ of extract dilutions was incubated for 5 min with $50 \mu$ l enzyme source. After incubation, $50 \mu \mathrm{l}$ of substrate was added and again incubated for $5 \mathrm{~min}$ at room temperature. The pre-substrate and post -substrate addition absorbance was recorded at $405 \mathrm{~nm}$ on a microplate reader. The increase in OD on substrate addition was obtained. Each test was carried thrice and the mean OD was used to quantify the percentage of $\alpha$-glucosidase inhibition. Acarbose was used as positive control with different doses. The dosage of acarbose and anthocyanin extract required to inhibit $50 \%$ of $\alpha$-amylase activity under the conditions was noted as the $\mathrm{IC}_{50}$ value.

Percentage $\alpha$-glucosidase inhibition was calculated according to the formula:

Percentage of inhibition $=\left[\left(\right.\right.$ Control $_{405}-$ Extract 405$\left.)\right] \times 100$

\section{Control 405}

\subsubsection{In vitro alpha amylase inhibition assay}

The assay was performed following the method of Hansawasdi et al ${ }^{9} .2 \mathrm{mg}$ Starch azure was suspended in 0.2 $\mathrm{mL}$ of Tris-HCl buffer ( $\mathrm{pH} 6.9,0.5 \mathrm{M})$ containing $\mathrm{CaCl}_{2}(0.01$ $\mathrm{M}$, substrate). The tubes containing substrate solution were heated for $5 \mathrm{~min}$ and then pre-incubated at $37^{\circ} \mathrm{C}$ for $5 \mathrm{~min}$. Purified anthocyanin extract from wild balsam species was dissolved in DMSO in order to obtain various doses of 50, $100,200,400$ and $500 \mu \mathrm{g} / \mathrm{mL}$. Anthocyanin extract of particular concentration was added to the tube containing the substrate solution. In addition, $0.1 \mathrm{~mL}$ of porcine pancreatic amylase in Tris-HCl buffer $(2 \mathrm{U} / \mathrm{mL})$ was also added. The reaction was carried out at $37^{\circ} \mathrm{C}$ for $10 \mathrm{~min}$. The reaction was arrested by adding $0.5 \mathrm{~mL}$ of $50 \%$ acetic acid in each tube. The reaction mixture was centrifuged at 3000 rpm for $5 \mathrm{~min}$ at $4^{\circ} \mathrm{C}$. The OD of resulting supernatant was recorded at $595 \mathrm{~nm}$. Acarbose, a known $\alpha$-amylase inhibitor was used as a standard drug. The experiments were repeated three times. The $\alpha$-amylase inhibitory activity was calculated by using the following formula:

The $\alpha$-amylase inhibitory activity =

$$
\left[\left(A_{c^{+}}-A_{c^{-}}\right)-\left(A_{s}-A_{b}\right)\right] /\left(A_{c^{+}}\right)-\left(A_{c-}\right) \times 100,
$$

where $A_{c+}, A_{c-}, A_{s}$, and $A_{b}$ are the absorbance of $100 \%$ enzyme activity (only solvent with enzyme), $0 \%$ enzyme activity (only solvent without enzyme), a test sample (with enzyme), and a blank (a test sample without enzyme), respectively. The concentration of acarbose and anthocyanin extract required to inhibit $50 \%$ of $\alpha$-amylase activity under the conditions was defined as the $\mathrm{IC}_{50}$ value.

\subsection{Statistical analysis}

SPSS 18.0 statistical software was used for data analysis. Data from different assay treatments were analyzed by oneway analysis of variance (ANOVA); The Student-NeumanKeuls post-hoc test was used to determine significance for individual experimental conditions. Differences with $P<$ 0.01 or $P<0.05$ were regarded as significant.

\section{RESULTS AND DISCUSSION}

\subsection{Anthocyanin content, purification and fractionation}

Anthocyanin content in the petals of wild Balsam species was quantified as $5.88 \mathrm{mg} / \mathrm{g}$. Purified anthocyanins after 3 step protocol was subjected to NMR and LC MS analysis (Fig.1, 2, 3) for their structural identification. The major fractions were hesperidin, dimethoxy antirrhinin and trimethoxy antirrhinin (Fig. 4: A, B, C). 


\section{M-H}
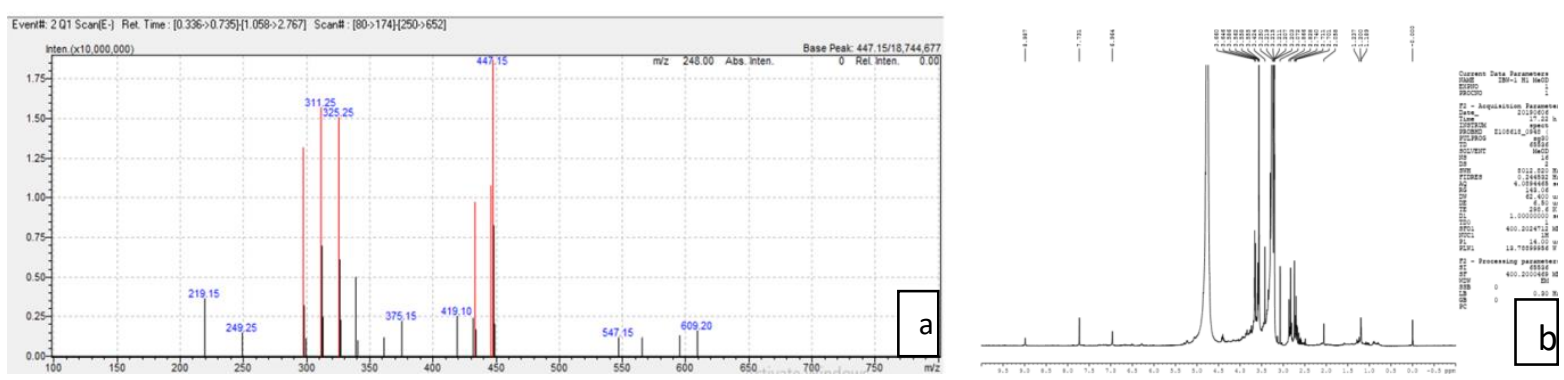

Fig. 1: (a) LC MS and (b) NMR spectrum of Hesperi1din from the wild Balsam

M-H
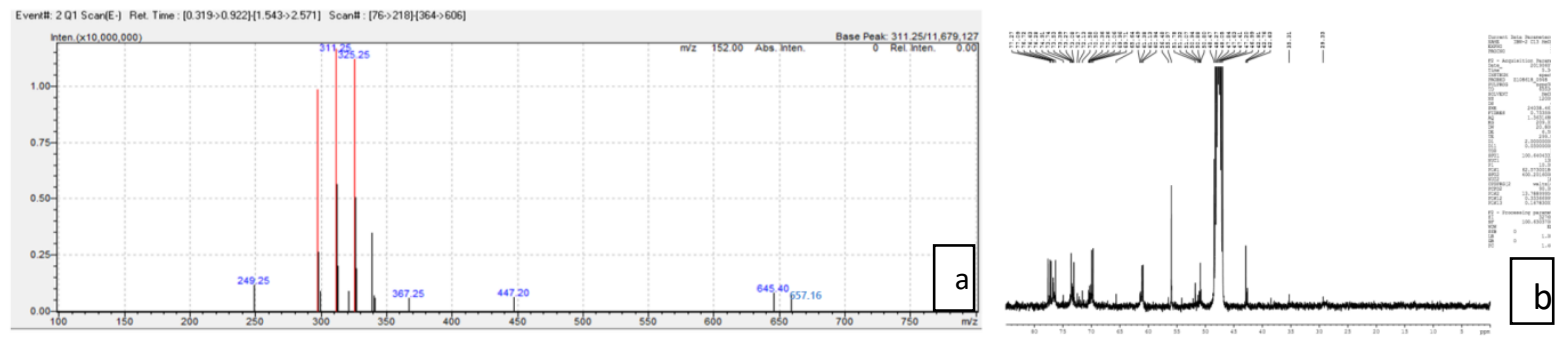

Fig. 2: (a) LC MS and (b) NMR spectrum of Dimethoxy antirrhinin from the wild Balsam

M-H
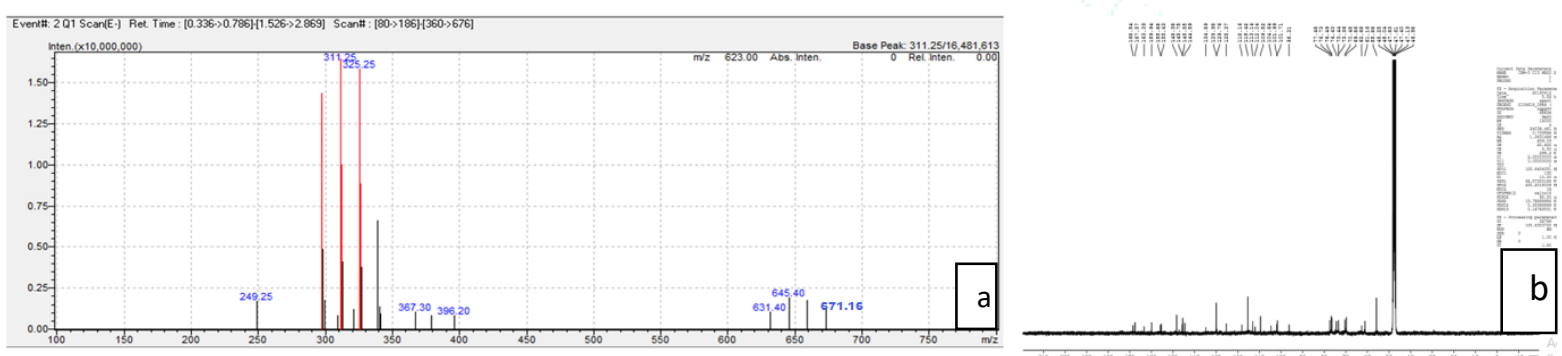

Fig. 3: (a) LC MS and (b) NMR spectrum of Trimethoxy antirrhinin from the wild Balsam.
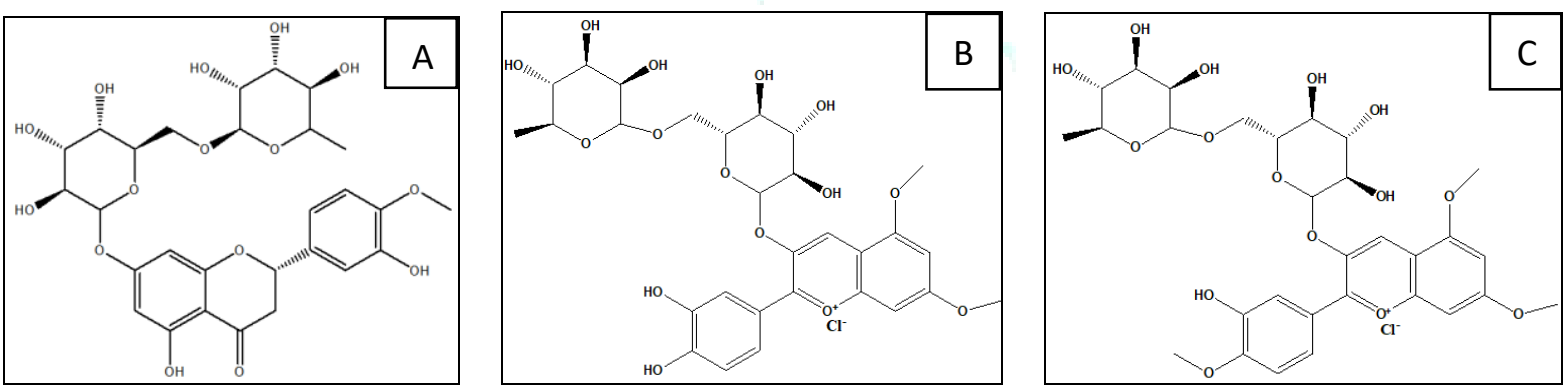

Fig. 4: Chemical structure of (A) Hesperidin $\left(\mathrm{C}_{28} \mathrm{H}_{34} \mathrm{O}_{15}\right)$ (B) Dimethoxy antirrhinin $\left(\mathrm{C}_{29} \mathrm{H}_{35} \mathrm{ClO}_{15}\right)(\mathrm{C})$ Trimethoxy antirrhinin $\left(\mathrm{C}_{30} \mathrm{H}_{37} \mathrm{ClO}_{15}\right)$

\subsection{In vitro Antidiabetic Activity}

\subsubsection{In vitro $\alpha$-amylase inhibitory activity}

The in vitro $\alpha$-amylase inhibitory potentiality of the purified anthocyanin extracts of wild balsam species was evaluated. The data displays a dose-dependent increase in the percentage of inhibitory activity against the $\alpha$-amylase enzyme. The purified anthocyanin extract $(50,100,200,400$ and $500 \mu \mathrm{g} / \mathrm{ml}$ ) of wild balsam exhibited potent $\alpha$-amylase inhibitory activity from 24.2 to $80.7 \%$ with an IC $_{50}$ value of $200 \mu \mathrm{g} / \mathrm{ml}$ extract (Table 1). Acarbose, the standard drug for $\alpha$-amylase inhibitor at a concentration of $50-500 \mu \mathrm{g} / \mathrm{ml}$, showed $\alpha$-amylase inhibitory activity from 27.1 to $83.2 \%$ with an $\mathrm{IC}_{50}$ value $189 \mu \mathrm{g} / \mathrm{ml}$ extract. So, it is possible to suggest that the extract may be used as starch blockers since it inhibits or delays the starch absorption into the body mainly via blocking the lysis of 1,4-glycosidic linkages of starch and other oligosaccharides into maltose, maltotriose and other sugars. In the present study, the extract of wild balsam showed maximum $\alpha$ - amylase inhibitory activity (IC 50 $=200 \mu \mathrm{g} / \mathrm{ml}$ extract) which could be attributed by the purified anthocyanin $(5.88 \mathrm{mg} / \mathrm{g})$. It is possible to suggest that polyphenolics are not only capable of mitigating oxidative stress but also inhibits carbohydrate hydrolyzing enzymes due to their ability to bind with proteins. The obtained results were in accordance with the studies in the species such as Vietnamese edible plants, Gymnema montanum, and Psidium guajava leaves respectively10, 11,12. 
Table 1. In vitro $\alpha$-amylase inhibitory potentiality of the purified anthocyanin extracts of wild balsam species

\begin{tabular}{|c|c|c|}
\hline \multirow{2}{*}{ Concentration $(\boldsymbol{\mu g} / \mathbf{m L})$} & \multicolumn{2}{|c|}{ Percentage inhibition } \\
\cline { 2 - 3 } & Anthocyanin & Standard: Acarbose \\
\hline 50 & 24.2 & 27.1 \\
\hline 100 & 39.60 & 33.31 \\
\hline 200 & 50.0 & 56.48 \\
\hline 400 & 63.92 & 73.12 \\
\hline 500 & 80.7 & 83.2 \\
\hline
\end{tabular}

\subsubsection{In vitro $\alpha$-glucosidase inhibitory activity}

Antidiabetic activity using $\alpha$ - glucosidase inhibitory assay of the purified anthocyanin extracts was narrated in the Table 2. The anthocyanin extract showed remarkable inhibitory action of $\alpha$-glucosidase enzyme. The percentage of inhibition at $50-500 \mu \mathrm{g} / \mathrm{ml}$ concentrations of wild balsam anthocyanin extract showed a concentration dependent increase in inhibition.

Table 2. In vitro $\alpha$-glucosidase inhibitory potentiality of the purified anthocyanin extracts of wild balsam species

\begin{tabular}{|c|c|c|}
\hline \multirow{2}{*}{ Sample concentration $(\boldsymbol{\mu g} / \mathbf{m L})$} & \multicolumn{2}{|c|}{ Percentage inhibition } \\
\cline { 2 - 3 } & Anthocyanin & Standard: Acarbose \\
\hline 50 & 18.5 & 50.01 \\
\hline 100 & 30.20 & 65.51 \\
\hline 200 & 34.40 & 68.66 \\
\hline 400 & 38.02 & 74.72 \\
\hline 500 & 50.03 & 85.27 \\
\hline
\end{tabular}

The percentage of inhibition varied from $18.5-50.03 \%$ for highest concentration to the lowest dose with an $\mathrm{IC}_{50}$ value $500 \mu \mathrm{g} / \mathrm{ml}$. Thus the inhibition of the activity of $\alpha-$ glucosidase by anthocyanin would retard the carbohydrate degradation which in turn reduce the absorption of glucose, as a result the reduction of post-prandial blood glucose level elevation.

In this study, the standard drug acarbose for the $\alpha$ glucosidase inhibitor at a concentration of $50-500 \mu \mathrm{g} / \mathrm{ml}$ showed $\alpha$-glucosidase inhibitory activity from 59.28 to $85.27 \%$ with an $\mathrm{IC}_{50}$ value $50 \mu \mathrm{g} / \mathrm{ml}$. This indicates that the anthocyanin is potent $\alpha$-amylase and $\alpha$-glucosidase inhibitor and comparable with acarbose. Thus, there is a positive relationship between the polyphenol content and their ability to inhibit intestinal $\alpha$-glucosidase and pancreatic $\alpha$ amylase.

Lee et al screened antidementia acetylcholinesterase inhibitors from the fruits and designed an optimal extraction conditions ${ }^{13}$. In vitro antidiabetic and antioxidant activities of methanol extract of Tinospora sinensis was described 14 . Antihyperglycemic, antidiabetic, and antioxidant effects of Garcinia pedunculata in rats was also proved ${ }^{15}$. Different studies have reported that dietary polyphenols including flavonoids and phenolic acids may inhibit $\alpha$-amylase and $\alpha$ glucosidase which inturn inhibit glucose absorption in the intestine by sodium-dependent glucose transporter 1 (SGLT1), stimulate insulin secretion, and reduce hepatic glucose output. Polyphenols may also increase insulindependent glucose uptake, activate 5' adenosine monophosphate-activated protein kinase (AMPK), modify the microbiome, and have anti-inflammatory effects. Detailed experimentation should be conducted to identify the exact mechanism. Some researchers showed that catechin treatment ameliorates diabetes and its complications in streptozotocin-induced diabetic rats ${ }^{16}$. Madhuri and Naik analyzed modulatory effect of garcinol in streptozotocininduced diabetic Wistar rats ${ }^{17}$. Some studies documented in vitro antioxidant, antidiabetic, cholinesterase and tyrosinase inhibitory potential of fresh juice from Citrus hystrix and $C$. maxima fruits ${ }^{18}$. Ocimum genera have been reported to have antidiabetic potentials. $O$. basilicum, $O$. tenuiflorum, $O$. sanctum, $O$. canum leaves have all been reported to exhibit strong inhibition against $\alpha$-amylase and $\alpha$ - glucosidase ${ }^{19}$. Studies revealed the preventive effects of Morus alba anthocyanins on diabetes in Zucker diabetic fatty rats ${ }^{20}$. It was proposed that inhibition of the activity of such alphaamylase and alpha-glucosidase would delay the degradation of carbohydrate, which would in turn cause a decrease in the absorption of glucose, as a result the reduction of postprandial blood glucose level elevation ${ }^{21}$. The antidiabetic and antioxidative potential of the blue congo variety of purple potato extract in streptozotocin-induced diabetic rats was explained 22 . Sundarrajan et al studied in-vitro hypoglycemic and glucose uptake activity of isolated compound from ethanolic leaf extract of Amaranthus tristis ${ }^{23}$. Researchers showed in vitro antidiabetic activity affecting glucose uptake in Hep G2 cells following their exposure to extracts of Lauridia tetragon ${ }^{24}$. Antidiabetic effect of ethanolic leaf extract of Phyllanthus amarus in alloxan induced diabetic mice was studied ${ }^{25}$. Recently, evaluated of hypoglycemic and antihyperglycemic effect of aqueousmethanolic leaves extract of two medicinal plants of Meghalaya in mice ${ }^{26}$. Similarly, confirmed the antidiabetic and antiobesity effects of plant extract from Cleome droserifolia ${ }^{27}$. The antidiabetic activity of Terminalia catappa leaf extracts in alloxan-induced diabetic rats was also proved 28 .

Antidiabetic activity of selected herbals such as bark of Eugenia jambolana, the whole plants of Phyllanthus niruri, seeds of Momordica charantia and leaves of Nyctanthes arbor-tristis was investigated. The results revealed that the aqueous extract showed better efficacy than the ethanolic extracts in all the treated extract in lowering the blood glucose levels in alloxan induced diabetic rats ${ }^{29}$. In vitro antioxidant and antidiabetic activity of methanolic fruit extract of medicinal plant Piper cubeba was evaluated. The treatment of the yeast cells with the methanolic extract revealed that the glucose uptake was found to increase in a dose dependent manner which amplifies its antidiabetic CODEN (USA): JDDTAO 
potentiality. This probable attribute is due to the bioactive polyphenols and flavonoids in the extract ${ }^{30}$. Thus, the obtained data in this study substantiates the antidiabetic possibilities of anthocyanins from the wild balsam species. This is the first report of in vitro antidiabetic activity of anthocyanin from the species.

\section{CONCLUSION}

The results of the present study showed that the wild balsam possess optimal level of anthocyanin content. In vitro alpha amylase and alpha glucosidase activity of anthocyanin from the I. balsamina floral extract was evaluated. Anthocyanin of Balsam species has been traditionally used as herbal medicine in folk remedies for curing multiple ailments. So, further in vivo studies are warranted to declare the anthocyanin of Balsam species as novel antidiabetic target for new drug designing.

\section{Conflict of interest}

The authors declare that they have no conflict of interest.

\section{REFERENCES}

1. Riddle MC, "Diabetes Care in 2020: Following and Leading the Stories of Diabetes", Diabetes Care, 2020; 43 (1):3-4

2. Fang JL, Jia SS, Lin Y, Yuan K, Jin SH, "Extraction, purification, content analysis and hypoglycemic effect of mulberry marc anthocyanin", Phcog Mag, 2020; 16:68-75.

3. Akindele AJ, Otuguor E, Singh D, Ota D, Benebo AS, "Hypoglycemic, antilipidemic and antioxidant effects of valproic acid in alloxan-induced diabetic rats", Eur J Pharmacol, 2015; 762:174-83

4. Lupascu FG, Giusca SE, Caruntu ID, Anton A, Lupus oru CE, Profire L, "The safety profile of new antidiabetic xanthine derivatives and their chitosan based formulations", Eur. J. Pharm. Sci, 2019; 127:71-78.

5. Adisakwattana S, Ngamrojanavanich N, Kalampakorn K, Tiravanitb W, Roengsumranb S, Yibchok-Anun S, "Inhibitory Activity of Cyanidin-3-rutinoside on $\alpha$-Glucosidase", Journal of Enzyme Inhibition and Medicinal Chemisty, 2004; 19(4):313316

6. Matsui T, Ueda T, Oki T, Sugita K, Terahara N, Matsumoto K, "Alpha-Glucosidase inhibitory action of natural acylated anthocyanins. 2. alpha-Glucosidase inhibition by isolated acylated anthocyanins", Journal of Agricultural and Food Chemistry, 2001; 49(4):1952-1956.

7. Sutharut J, Sudarat J, "Total Anthocyanin Content and Antioxidant Activity of Germinated Colored Rice", Inter Food Res. J, 2012; 19:215-221.

8. Kim JS, Kwon CS, Son KH, "Inhibition of alpha-glucosidase and amylase by luteolin, a flavonoid", Biosci Biotechnol Biochem, 2000; 64(11):2458-61

9. Hansawasdi C, Kawabata J, Kasai T. Alpha-amylase inhibitors from roselle (Hibiscus sabdariffa Linn.) tea. Biosci Biotechnol Biochem. 2000; 64:1041-43

10. Mai TT, Thu NN, Tien PG, Van Chuyen N, "Alpha-glucosidase inhibitory and antioxidant activities of Vietnamese edible plants and their relationships with polyphenol contents", J Nutr Sci Vitaminol (Tokyo), 2007; 53:267-76.

11. Ramkumar KM, Thayumanavan B, Palvannan T, Rajaguru P, "Inhibitory effect of Gymnema montanum leaves on $\alpha$ glucosidase activity and $\alpha$-amylase activity and their relationship with polyphenolic content", Medicinal Chemistry Research, 2010; 19(8):948-961.

12. Manikandan R, Vijaya A, Muthumani GD, "Phytochemical and in vitro anti-diabetic activity of methanolic extract of Psidium guajava leaves", International Journal of Current Microbiology and Applied Sciences, 2013; 2(2):15-19

13. Lee EN, Song JH, Lee JS, "Screening of a potent antidementia acetylcholinesterase inhibitor-containing fruits and optimal extraction conditions", Kor. J. Food Nutr, 2010; 23:318-323.
14. Banerjee A, Maji B, Mukherjee S, Chaudhuri K, Seal T, "In Vitro Antidiabetic and Anti-oxidant Activities of Methanol Extract of Tinospora sinensis", Journal of Applied Biology \& Biotechnology, 2017; 5(03):061-067

15. Ali MY, Paul S, Tanvir EM, Hossen MS, Rumpa NN, Saha M, Bhoumik NC, Islam MA, Hossain MS, Alam N, Gan SH, Khalil MI "Antihyperglycemic, Antidiabetic, and Antioxidant Effects of Garcinia pedunculata in Rats. Evidence-Based Complementary and Alternative Medicine", 2017; Article ID 2979760

16. Samarghandian S, Nezhad MA, Farkhondeh T, "Catechin treatment ameliorates diabetes and its complications in streptozotocin-induced diabetic rats," Dose-Response, 2017; $15(1)$.

17. Madhuri K, Naik PR, "Modulatory effect of garcinol in streptozotocin-induced diabetic Wistar rats," Archives of Physiology and Biochemistry, 2017; 201:1-8

18. Abirami A, Nagarani G, Siddhuraju P, "In vitro antioxidant, antidiabetic, cholinesterase and tyrosinase inhibitorypotential of fresh juice from Citrus hystrix and C. maxima fruits", Food Science and Human Wellness, 2014; 3:16-25

19. Ononamadu CJ, Alhassan AJ, Imam AA, Ibrahim A, Ihegboro GO, Owolarafe AT, Sule MS, "In vitro and in vivo evaluation of the antidiabetic and antioxidant activity of methanol extract/ solvent fractions of Ocimum canum leaves", Caspian J Intern Med, 2019; 10(2):162-175

20. Sarikaphuti A, Nararatwanchai $T$, Hashiguchi $T$, Ito $T$, Thaworanunta S, Kikuchi K, Oyama Y, Maruyama I, Tancharoen S, "Preventive effects of Morus alba L. anthocyanins on diabetes in Zucker diabetic fatty rats", Experimental And Therapeutic Medicine,2013; 6:689-695

21. Rhabaso Lhoret R, Chiasson JL, Glucosidase inhibitors. In: Defronzo RA, Ferrannini E, Keen H, Zimmet P. (Eds.), International Textbook of Diabetes Mellitus, Vol. 1, third ed. John Wiley and Sons Ltd., UK; 2004. P. 901-914

22. Strugała P, Dzydzan O , Brodyak I , Kucharska AZ , Kuropka P, Liuta M, Kaleta-Kuratewicz K, Przewodowska A, Michałowska D, Gabrielska J, Sybirna N, "Antidiabetic and Antioxidative Potential of the Blue Congo Variety of Purple Potato Extract in Streptozotocin-Induced Diabetic Rats", Molecules 2019; 24(17):3126

23. Sundarrajan T, Velmurugan V, Manikandan K, Jothieswari D, "A study of In-vitro hypoglycemic and glucose uptake activity of isolated compound from ethanolic leaf extract of Amaranthus tristis Linn.", Phcog Res, 2019; 11:37-40

24. Odeyemi S, Dewar J, "In Vitro Antidiabetic Activity A_ecting Glucose Uptake in HepG2 Cells Following Their Exposure to Extracts of Lauridia tetragona (L.f.) R.H.", Archer Processes, 2020; 8:33;

25. Shetti AA, Sanakal RD, Kaliwal BB, "Antidiabetic effect of ethanolic leaf extract of Phyllanthus amarus in alloxan induced diabetic mice", Asian Journal of Plant Science and Research, 2012; 2(1):11-15

26. Rynjah CV, Boruah P, Majaw S, "Evaluation of hypoglycemic and antihyperglycemic effect of aqueous-methanolic leaves extract of two medicinal plants of Meghalaya in mice", International Journal of Pharmacological Research, 2016; 6(7):256-263

27. Helal EGE, Sharaf HA, Mattar FE, "Anti - diabetic and anti-obesity effects of plant extract from Cleome droserifolia (SAMWA)", The Egyptian Journal of Hospital Medicine, 2002; 9:85 - 101

28. Ahmed SM, Vrushabendra Swamy BM, Dhanapal PGR, Chandrashekara VM, "Anti-Diabetic Activity of Terminalia catappa Linn. Leaf Extracts in Alloxan-Induced Diabetic Rats", Iranian Journal Of Pharmacology \& Therapeutics, 2005; 4(1):3639

29. Nagar R, Patel R, “Anti-diabetic Activity of Few India Indigenous Medicinal Plants", Int. J. Pharm. Sci. Drug Res, 2019; 11(6):278283.

30. Muchandi A, Jadhav AS, Patil SB, Patil SA, Jadhav NB, "Antioxidant and In Vitro Antidiabetic Activities of Methanol Extract of Piper cubeba L.," International Research Journal of Pharmacy and Medical Sciences (IRJPMS), 2018; 1(3):1-4 